\title{
Scientific literacy, pleasure and aesthetics: the collaborative virtual worlds that Galileo could not foresee
}

\author{
Daiana R. Bortoletto ${ }^{1}$, Mariângela de Oliveira-Abans ${ }^{1}$, Propércio G. \\ Guida Júnior $^{1}$, Iranderly F. de Fernandes ${ }^{1,3}$, and Rafael Santos ${ }^{2}$ \\ ${ }^{1}$ Ministério de Ciência e Tecnologia/Laboratório Nacional de Astrofísica, \\ R. Estados Unidos, 154, Itajubá, MG, CEP: 37504-364, Brazil \\ e-mail: dbortoletto@lna.br, mabans@lna.br, pguida@lna.br, ifernandes@lna.br \\ ${ }^{2}$ Ministério de Ciência e Tecnologia/Instituto Nacional de Pesquisas Espaciais, \\ Av. dos Astronautas, 1.758, Jd. Granja, CEP: 12227-010, São José dos Campos, SP, Brazil \\ e-mail: rafael.santos@lac.inpe.br \\ ${ }^{3}$ Universidade Estadual de Feira de Santana/Departamento de Física, Av. Transnordestina, \\ S/N, Novo Horizonte, CEP: 44036-900, Feira de Santana, BA, Brazil \\ e-mail: ifernandes@lna.br
}

\begin{abstract}
We present the various activities and infrastructure dedicated to educational scientific and technological outreach of the MCT/Laboratório Nacional de Astrofísica, Brazil and how useful they are in diminishing the scientific illiteracy of the layman, the young, the senior citizens and the handicapped. We also explore the future endeavors and commitments that scientists and educators are to face in order to bring enlightenment.
\end{abstract}

Keywords. astronomy, outreach, image bank, virtual observatory, remote observation.

\section{Introduction: the desperate needs}

These are times of strong contrasts: on one side, science and technology advance rapidly and influence civilization on a world-wide scale, on the other side, countries with poor socio-economical realities tend to fall more and more behind. It is important to mitigate these differences and provide the means for the common people to benefit from the technological advances and the chances offered by globalization. The MCT/Laboratório Nacional de Astrofísica - LNA, is a niche of highly specialized technology in the development of instruments for professional astronomical observatories and as such it is a knowledge and technology generator. It is commited to educational outreach because it is only through conveying information to the layman and media agents that individuals may be aware of the progress around them and so become fully conscious citizens, critic and capable of making those choices that are best for them.

Ground Astronomy has experienced extraordinary development and Brazil is perfectly inserted in that context through the LNA/Observatório do Pico dos Dias (OPD, web site: http://www.lna.br/opd/opd.html), the participation in the Gemini Observatory and the SOAR Telescope, and the use of the Canada-France-Hawai'i Telescope.

Astronomy is a powerful tool for promoting scientific literacy and pleasant education. This promising scenario, nonetheless, contrasts with the reality in Brazilian, where very rudimentary astronomical concepts are presented to school students by teachers educated in different areas. To make things worse, a large fraction of the professional scientific community is still far from the general public and frequently can not communicate very well with the media. This is one of the characteristics of social exclusion. 


\section{Galileo today}

Four hundred years ago, Galileo employed the most advanced technology available at his time to begin the exploration of the skies. Through his telescope, he saw other worlds, and this opened the curtains of a larger and - who knows? - maybe a populous Universe. Today, scientists and technologists still pursue the scientific explanations and state-of-the-art technological solutions to challenges that Nature poses. Should Galileo live in these days, he would have been educated in schools with resources that were unimaginable in the past centuries. He would have such real and virtual infrastructure that he would certainly be seeking moons around extra-solar planets in very sophisticated ways. There are several scientific products and services that are offered to the community, media and especially to schools.

A first example is the Observatório no Telhado ("Observatory on the Roof"). Its 30cm telescope will be part the Telescópios na Escola ("Telescopes at School") Brazilian Network and will also be used by schools of the Gemini Observatory and SOAR Telescope member countries.

A second one is the Virtual Image Bank (BIMA), which provides untrained users with a web interface that allows the display and use of astronomical images for, e.g., data reduction training and/or resources for the participants of the Olimpíada Brasileira de Astronomia, Astronáutica e Energia - OBA (Brazilian Astronomy, Astronautics and Energy Olympiads), or moments of aesthetic contemplation.

We have also developed the PocketVO with INPE (MCT/Instituto Nacional de Pesquisas Espaciais), a simple web-based tool for viewing images and data using the Virtual Observatory that can be used for both astronomical research and education.

\section{Observatory on the Roof}

A building of highly specialized workshops and laboratories dedicated to the design and construction of astronomical instruments was inaugurated at LNA's headquarters in 2006. A conference room for 80 people, the entrance hall and part of the roof area are used to display technical and astronomical exhibits and experiments, public talks, star gazing (see Figure 1), movies and so on.

The Observatório no Telhado (OnT - Observatory on the Roof) consists of a large open area surrounded by benches and garden, a telescope and dome tower and a control room, allowing for use either during the day or night. The 12-inch Meade telescope can be equipped with an SBIF CCD direct camera or a SGS SBIG self-guiding spectrograph. The OnT has already been used not only for star parties and the III Star Count, but also for talks and slides and video presentations for schools and general public. It should be operational by mid- 2010 .

What are the main objectives?

- complement the science contents of basic and high school of the surrounding regions;

- promote day and night sky gazing and observations of astronomical serendipitous and regular phenomena, such as comets and eclipses;

- allow for in situ and remote observations by schools in Brazil and the partner countries of the Gemini Observatory and SOAR Telescope;

- help teachers with correct astronomical concepts and recent discoveries;

- collaborate with teachers in arousing the interest in sciences from basic school level on, through the application of simple and atractive activities;

- allow handicapped people to have access to a telescope and astronomers;

- clarify the problem of light pollution to children and the layman; 


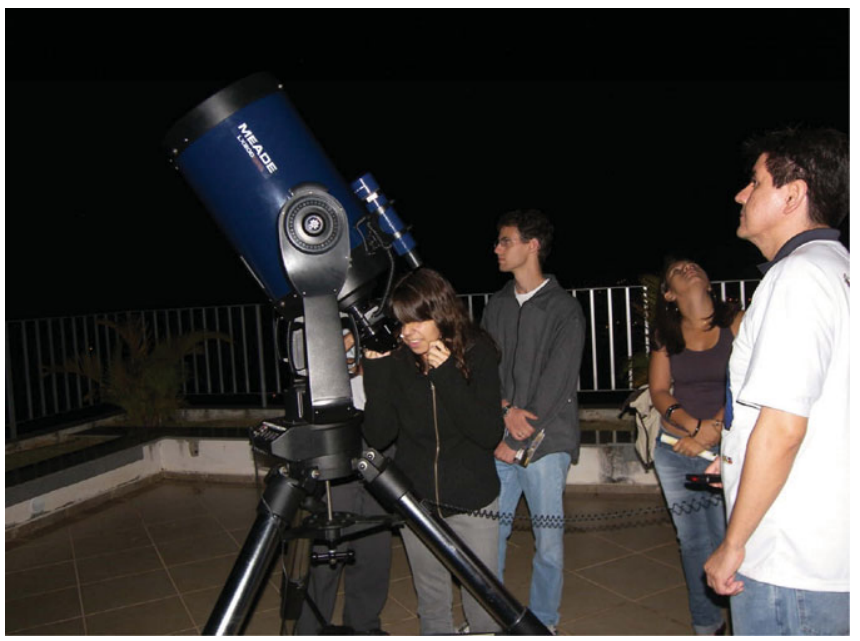

Figure 1. VI National Science and Techonolgy Week, OnT/LNA, 2009.

- take advantage of the interdisciplinarity of Astronomy to promote the integrated work of teachers of different areas of knowledge, different schools and different cities;

- to allow the use by amateurs, training technicians, physics undergraduates, offering them the chance of participating in scientific and educational reasearch.

\section{Telescopes at School}

TnE stands for Telescópios na Escola, and a full description of the project can be found at http://telescopiosnaescola.pro.br/. Through the remote use of small telescopes around the country, students and teachers become Universe explorers, choosing the objects to observe, planning the night runs, working with the data and interacting with TnE's support members. TnE and OnT share the same objectives and methodology.

Thousands of Brazilian students have already taken advantage of the TnE telescopes and instructional material available online, and have seen new small observatories grow throughout the country. These have become new true science centers.

One of the partner institutions (Instituto de Astronomia, Geofísica e Ciências Atmosféricas - IAGUSP) has facsimiles of the complete work of Galileo, in particular, his observations notes, which are invaluable.

\section{Virtual Image Bank}

In the context of the International Year of Astronomy - IYA2009 and its offspring, the Rede Brasileira de Astronomia (RBA, Brazilian Astronomical Network), LNA is a Local Node and so is committed to offering several services and products to the media and the community, mainly those related to formal and informal teaching.

A wide plan of improvement of LNA's outreach infrasctructure is presently being undertaken. The Outreach and Teaching of Astronomy Portal (Portal de Divulgação e Ensino - http://www.lna.br/ divulg/) received a boost through the implementation of the Virtual Image Bank (BIMA), which contains institutional, historical and astronomical low- and high-resolution images. One of us (D. Bortoletto) received a CNPq scholarship for the development of the BIMA site (see Figure 2). 


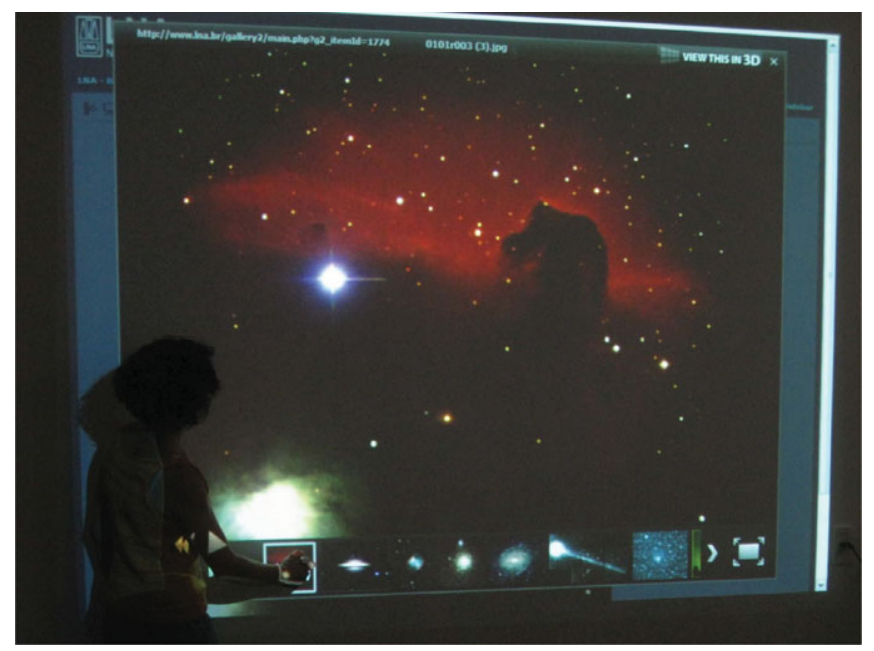

Figure 2. A BIMA window projected onto the wall. The user browses the images with the help of an infrared pen and a Nintendo Wii control.

Internet is the most accessible way for the public and the media and so is a good tool for disseminating scientific information. BIMA should turn into a trustable window of Brazilian astronomical results and a suitable resource for educational projects.

The images have been organized in directories (telescopes, observatories, instruments, laboratories and workshops, research results, outreach events and various classes of astronomical objects) and the Bank is interesting for the public of all ages.

Based on the bank, learning materials (including playgames) are to be dedicated, as a first step, to teachers and students of fundamental and high school grades. At present, it is possible to solve puzzles online (see Figure 3), simply choosing one image from a suitably selected list and specifying the number of pieces, which allows its use from small children on. More products for various media are to be offered in the future.

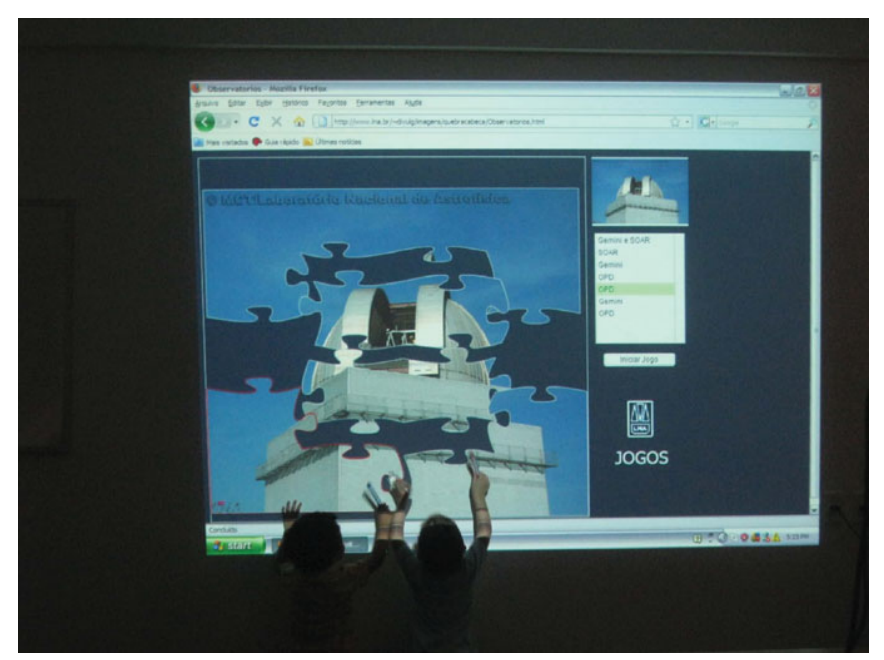

Figure 3. Children playing with virtual puzzle on the wall via infrared pen and a Nintendo Wii control. 


\section{PocketVO}

We have developed the PocketVO (http://www.lac.inpe.br/ rafael.santos/pocketvo. jsp) with MCT/Instituto Nacional de Pesquisas Espaciais - INPE. It is a simple, easy-touse, interactive tool to get images from different telescopes in different wavelenghts. Created specifically for untrained users, including teachers, students, amateur astronomers and researchers new to VO-enabled astronomy, it transparently allows access to information from different services through a unified interface. It is written in Java and works in any computer that has a Java Runtime Environment, version 5 or later, installed.

PocketVO's graphical user interface provides windows to see specific regions in the sky (see Figure 4), which can show one, two or three different wavelengths at the same time, so that users can easily see an object, e.g., in visible and X-Ray images. Regions can be entered directly in right ascension and declination coordinates or by object's name. Simple navigation controls allow the pan and zoom of the image. The various windows' configurations can be saved in files and shared with other users. Those files can be loaded either from local files or from URLs, making the sharing of data very simple.

Some possible extensions of these materials are: a digital whiteboard (already in use) and the development of a digital table with exchangeable modules according to the astronomical topics of interest. In the future, suitable interfaces will connect BIMA and PocketVO to the digital table and the whiteboard, a technology that will be available to schools, planetaria and science clubs due to its low cost.

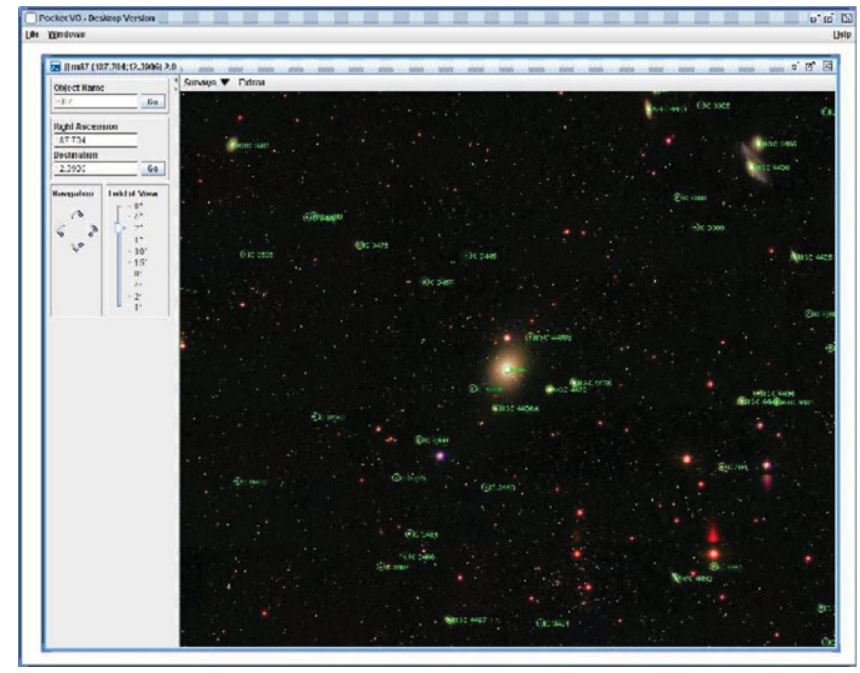

Figure 4. Pocket-VO's graphical user interface.

\section{Concluding remarks}

In the early 1600's, Galileo used a refracting telescope to observe celestial objects and may be considered the father of modern science. His astronomical research gave rise to a plethora of scientific endeavours, some of which are named after him.

The results of LNA's initiatives will be felt in various time scales. Beyond the present satisfaction of public outreach events and multimedia materials, the knowledge and experience aquired in the joint work with teachers and students will be gradually employed. The number of students interested in exact sciences will increase, and some of them 
will return to the LNA as undergraduates and graduates engaged in astronomical research and instrument development. As a byproduct, the results of the high school national evaluation, ENEM (http://www.enem.inep.gov.br/index.php), will be better and the participation in astronomical olympiads will be larger.

As time goes by, people will be aware of the science and technology their country produces and as such they will be citizens to the full extent of the word - and in pretty much less than 400 years.

\section{Acknowledgements}

We thank the MCT/LNA for the PCI Scholarships 38.0787/2009-1 and 381.671/2005-4, the John Hopkins University/NVO and the Scientific Organising Committee of IAUS269 for the partial grant. 